\title{
Visible-near Infrared (VIS-NIR) Spectroscopy as a Rapid Measurement Tool to Assess the Effect of Tillage on Oil Contaminated Sites
}

\author{
Douglas Reward Kokah ${ }^{1,2, ~ *, ~ F o u ~ A y e b a t i n ~}{ }^{3}$, Egai Ayibawari Obiene ${ }^{4}$ \\ ${ }^{1}$ School of Water, Energy and Environment, Cranfield University, Cranfield, UK \\ ${ }^{2}$ National Agency for Science and Engineering Infrastructure, Garki, Abuja, Nigeria \\ ${ }^{3}$ Center for Occupational Health and Safety, University of Port Harcourt, Port Harcourt, Nigeria \\ ${ }^{4}$ Department of Geology, University of Benin, Benin City, Nigeria
}

\section{Email address:}

rewardkdouglas@gmail.com (D. R. Kokah),ayebatinf@gmail.com (F. Ayebatin), aegai19@yahoo.com (E. A. Obiene)

*Corresponding author

\section{To cite this article:}

Douglas Reward Kokah, Fou Ayebatin, Egai Ayibawari Obiene. Visible-near Infrared (VIS-NIR) Spectroscopy as a Rapid Measurement Tool to Assess the Effect of Tillage on Oil Contaminated Sites. Engineering and Applied Sciences. Vol. 4, No. 6, 2019, pp. 135-143.

doi: 10.11648/j.eas.20190406.11

Received: September 22, 2019; Accepted: September 26, 2019; Published: November 7, 2019

\begin{abstract}
This study assessed the potential of using visible-near infrared diffuse reflectance spectroscopy to determine the effect of tillage (ploughing) on oil-contaminated sites. Crude oil contaminated samples were collected from the Ikarama, Bayelsa State, Niger Delta, Nigeria. 62 and 20 samples were collected from untilled and tilled (ploughed) sites, respectively. All samples were analysed in the laboratory with an Analytical Spectral Device spectrometer with a spectral range of 350 to $2500 \mathrm{~nm}$. Principal component analysis was performed on the soil spectral data using chemometric. Sequential ultrasonic solvent extraction was also carried out followed by gas chromatography coupled to mass spectrometry analysis to validate the visible-near infrared diffuse reflectance spectroscopy sensitivity and ability to detect change due to hydrocarbons profile changes. $27 \%$ and $15 \%$ concentrations of polycyclic aromatic hydrocarbons were present in the untilled and tilled sites, respectively. Gas Chromatography-Mass Spectrometry analysis also showed that PAHs and allkanes concentrations in the untilled site ranged from 0.05 to $48.493 \mathrm{mg} / \mathrm{kg}$ and 0.07 to $528.147 \mathrm{mg} / \mathrm{kg}$, respectively. For the tilled (ploughed) site, the concentrations for polycyclic aromatic hydrocarbons and alkanes quantified by Gas Chromatography-Mass Spectrometry ranged from 0.04 to $0.742 \mathrm{mg} / \mathrm{kg}$ and 0.06 to $159.280 \mathrm{mg} / \mathrm{kg}$, respectively. In addition, non-metric Multidimensional scaling was carried out using Primer version 6 to investigate the statistical significance of the hydrocarbon profiles and concentrations of the samples. To minimise the extent of overlap of the samples, the 82 samples collected were reduced to 49 samples (43 untilled and 6 tilled). Results show that visiblenear infrared diffuse reflectance spectroscopy may be a valuable tool for grouping hydrocarbon contaminated soils into hydrocarbon content and concentrations.
\end{abstract}

Keywords: Visible-near Infrared Spectroscopy, Hydrocarbons-contaminated Soils, Tillage, Principal Component Analysis, Niger Delta

\section{Introduction}

There are millions of hydrocarbon contaminated soils globally, and upon the pressure on land for food production, increasing pace of urbanization and the associated risk there is emergent need for rapid identification and remediation of these contaminated sites [1-3]. Petroleum hydrocarbons (PHCs) encompass hundreds of various organic compounds such as aromatic, aliphatic and traces of heterocyclic compounds (nitrogen, hydrogen, sulphur) from light gases to residues, which are well-known environmental contaminants [4-5]. Thus, there is a need for analytical techniques to rapidly and cost-effectively discriminate these chemicals. 
A considerable amount of literature has been published on the application of the vis-NIR spectroscopy for rapid estimation of soil hydrocarbon contamination. For example, Okparanma et al [6] assessed the ability of visNIR diffuse reflectance spectroscopy (DRS) with a spectral range of $350-2500 \mathrm{~nm}$ for the measurement of petroleum hydrocarbon contamination in soils. The authors used SUSE-GC as a validating tool and they achieved a coefficient of determination $\left(\mathrm{R}^{2}\right.$ of $\left.0.77-0.89\right)$, residual prediction deviation (RPD of 1.86-3.12), and root-mean-square error (RMSE of $1.16-1.95 \mathrm{mg} / \mathrm{kg}$ ) for the partial least square (PLS) regression calibration model. They recommended that the method may be promising for quick evaluation of the spatial variability of polycyclic aromatic hydrocarbons (PAHs) in petroleum-released soils, and assist site risk assessment. In another study Okparanma et al [7] investigated the opportunity of employing vis-NIR DRS for mapping of PAH and total toxicity equivalent concentration (TTEC) of PAH mixture in different petroleum discharged sites in Niger Delta, Nigeria. The t-test results showed no significant $(\mathrm{p}>0.05)$ discrepancies between PAH soil maps and TTEC obtained from vis-NIR-based prediction data. The authors concluded that vis-NIR technique can provide a rapid means for monitoring hydrocarbon contamination in petroleum-discharged area. In a previous study [8] used 150 diesel-seeded soils to assess the applicability of visNIR DRS (350-2500 $\mathrm{nm})$ to evaluate phenanthrene in soils. They used PLS regression with cross-validation and obtained RPD of 2.0 and 2.32, root mean square error of prediction (RMSEP of 0.21 and $0.25 \mathrm{mg} / \mathrm{kg}$ ), and coefficient of determination $\left(\mathrm{R}^{2}\right.$ of 0.75 and 0.83 ) for validation and calibration, respectively. The authors acknowledged that Vis-NIR spectrometer is fit for the prediction of phenanthrene in contaminated soils. PLSR modeling approach was used to achieve RMSEP of 0.2010 $\mathrm{mg} / \mathrm{kg}$, RPD of 2.75 and $\mathrm{R}^{2}$ of 0.89 for the calibration model by vis-NIR DRS [9]. The authors suggest the possibility of the technique to quantitatively characterize PAH in diesel-contaminated soils. An ordinal logistic regression method was utilised to predict total PAHs and benzo [a] pyrene using vi-NIR technique [10]. The result showed a good accuracy $(90 \%)$ and moderate to high false-positive rate at low and high total PAH threshold, respectively. Vis-NIR DRS (350-2500) was used to identify petroleum hydrocarbon contamination in soils [11]. To achieve their research objective, 46 contaminated and control samples were collected from Louisiana, USA and took both field-moist intact and air-dry scans with vis-NIR DRS. With PLS regression and boosted regression tree (BRT) calibration models, the authors obtained $\mathrm{R}^{2}$ of 0.64 and RPD of 1.70 as best TPH from the field-moist scans, since the air-dried scans yielded 0.57 and 1.25 for $\mathrm{R}^{2}$ and $\mathrm{RPD}$, respectively. Thus, they concluded that within the visible and near infrared range, there is the possibility of vis-NIR DRS as proximal soil sensing tool for petroleum hydrocarbons. The applicability of vis-NIR in a control sample seeded with diesel crude oil, control soil mixed with oil, and actual TPH contents was previously examined [12]. With PLS cross-validation for seeded minerals, NIRS recorded RMSE of $4500-8000 \mathrm{mg} / \mathrm{kg}$ out of the TPH range of 0 $100000 \mathrm{mg} / \mathrm{kg}$. To examine the detection ability of visNIR for TPH in soils, [12] utilized contaminated soils with definite concentration of petroleum. Measured results from different well-known laboratories in Israel compared with vis-NIR prediction. The authors observed discrepancies between those laboratory results. However, a satisfactory correlation was established from the plot of reflectance spectroscopy and the laboratories $\mathrm{TPH}$ results versus projected TPH results. Consequently, they infer that the accuracy of vis-NIR spectroscopy technique was as promising as the commercial laboratories therefore could be a feasible on-line sensing tool. To date, there is no study yet in the open literature on assessing whether vis-NIR can be used to discriminate of oil contaminated soil samples that underwent some form of treatment such as tilling (ploughing). Thus, the present paper evaluates the potential of vis-NIR DRS $(350-2500 \mathrm{~nm})$ to differentiate two set of samples collected on an oil contaminated site in the Niger Delta region where tillage (ploughing) was applied on one area of the site. In addition, soil samples were analysed using SUE-GC to characterise the hydrocarbon profiles and concentrations in the oil-contaminated soil samples and validate the visNIR DRS sensitivity and ability to detect change due to hydrocarbons profile changes.

\section{Materials and Methods}

\subsection{Soil Samples Collection}

A total of 82 soil samples untilled $(n=62)$ and tilled $(n=20)$ were collected from an oil spill site in Ikarama, Okordia Clan Bayelsa State, Niger Delta, Southern Nigeria in August 2015 (Figure 1). It is worth noting that the study area has a tropical rain forest climate characterised by two seasons: the rainy season lasts for about 7 months between April and October with an overriding dry period in August (known as August break); and the dry season lasts for about 4 months, between November and March. The temperature varies between 25 and $35^{\circ} \mathrm{C}$ in August. Figure 1 shows the sampling location. All soil samples were collected from top $0-15 \mathrm{~cm}$. Samples were kept in a fridge at $4^{\circ} \mathrm{C}$ until analysis. 

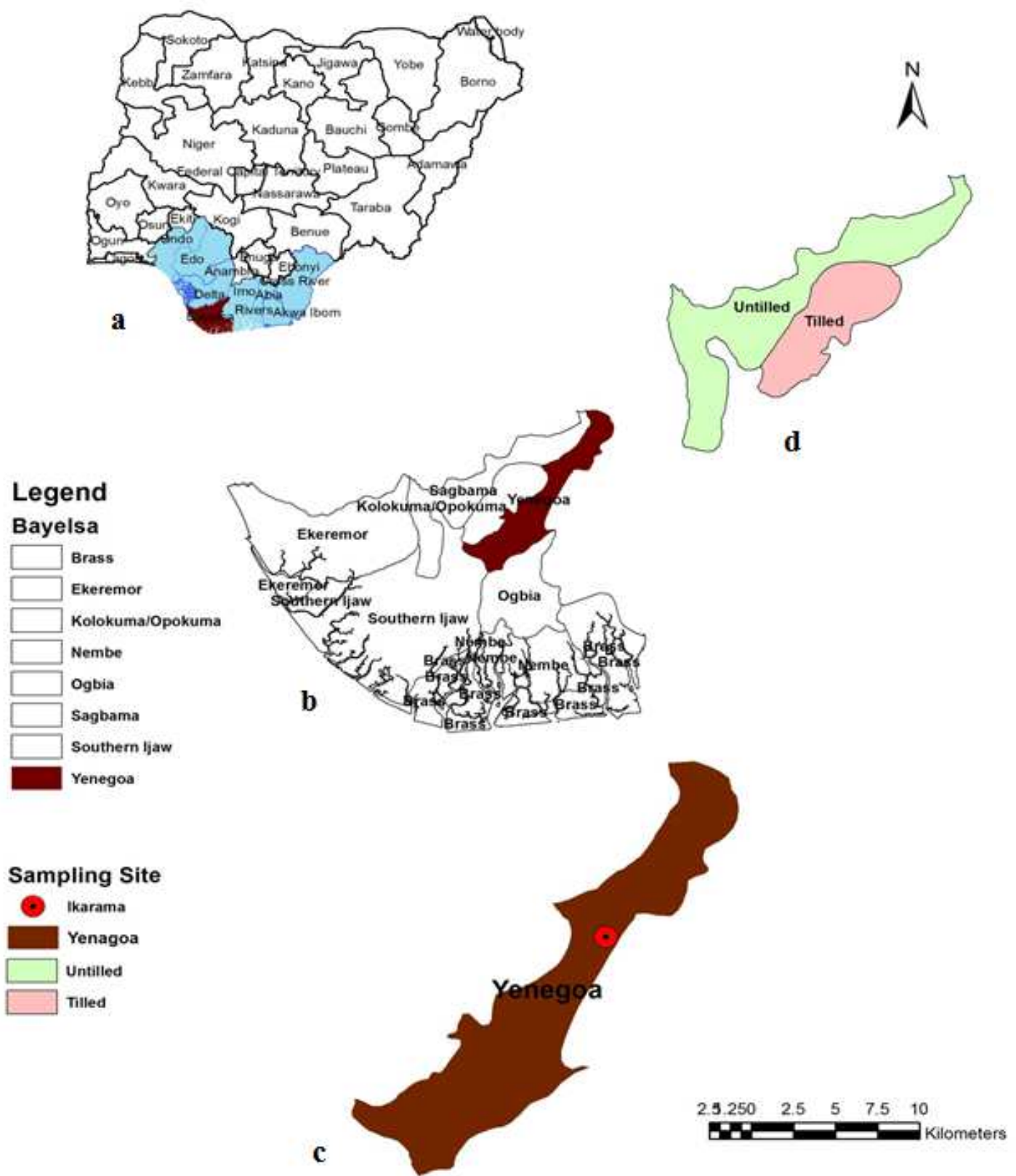

Figure 1. (a) Nigeria, with Niger Delta in blue and Beyelsa State in dark red, (b) Bayelsa State, with Yenagoa in dark red, (c) Ikarama in Yenagoa Local Government Area (sampling location) and (d) untilled and tilled (ploughed) sites.

\subsection{Measurement of Soil pH}

Soil $\mathrm{pH}$ was measured following Standard Operating Procedure (SOP) on the British Standard BS ISO 10390:2005 Determination of $\mathrm{pH} 50 \mathrm{ml}$ deionised water was added to $10 \mathrm{ml}$ brass scoop air-dried soil sample followed by shaking side-to-side using a mechanical shaker at $300 \mathrm{~min}^{-1}$ for 60 minute \pm 10 minutes and allowed to settle between 1 to $3 \mathrm{hr}$. Prior to measuring the $\mathrm{pH}$ of the sample, the suspension was further shake thoroughly and reading was recorded (Table 1) with a $\mathrm{pH}$ meter at stabilisation value as the suspension settles down.

\subsection{Determination of Total Organic Carbon in Soil}

The total organic carbon (TOC) was determined by Vario
III Elemental Analyser using SOP based on British Standard BS 7755 Section 3.8: 1995 Determination of organic and total carbon after dry combustion (elemental analysis) which is identical to ISO 10694:1995. Soil samples were air-dried; hand-grinded and sieved with $2.00 \mathrm{~mm}$ sieve. Sieved samples were machine grinded at 1 minute $300 \mathrm{rpm}$, ovendried at $150^{\circ} \mathrm{C}$ for $2 \mathrm{hr}$ and then cooled using desiccators. Less than $100 \mathrm{mg}$ (say $67-88 \mathrm{mg}$ ) of the resulting sample was weighed into a silver boat and put in a glass Petri dish, added 3 drops of $4 \mathrm{ml} / 1$ hydrochloric acid (HCL) to saturate the soil and remove any carbonates present. The final sample was kept for half an hour to allow reactions to occur to remove the inorganics, and oven-dried for another $4 \mathrm{hr} \pm 15$ minutes at $90^{\circ} \mathrm{C}$. After drying, samples were tightly packed in a silver-foil capsule into a larger aluminium-foil capsule 
and loaded into a carousel of the automotive sample feeder, heated to at least $900^{\circ} \mathrm{C}$ on a flow of oxygen-containing gas devoid of $\mathrm{CO}_{2}$ for the determination of the soil TOC. The results are shown in Table 1 below.

\subsection{Particle Size Determination}

Particle size was determined using SOP based on British Standard BS 7755 Section 5.4:1995 Determination of particle size distribution in mineral soil mineral-Method by sieving and sedimentation which is identical to ISO 11277:1998. Soil samples were air-dried, hand-grinded and sieved with a $2 \mathrm{~mm}$ sieve. $10 \mathrm{ml}$ brass scoop soil sample was measured into a polycarbonate bottle. $30 \mathrm{ml} \pm 1 \mathrm{ml}$ and $25 \mathrm{ml} \pm 2.5 \mathrm{ml}$ of deionised water and hydrogen peroxide were added, respectively. The hydrogen peroxide helps to burn the organic matter of the soil. The resulting solution was heated for $2 \mathrm{hr}$ at $100^{\circ} \mathrm{C} \pm 2^{\circ} \mathrm{C}$. Octan-2-ol was added to suppress frothing (excess foaming). By means of a dispenser, deionised water was added to make up $200 \mathrm{~g} \pm 1 \mathrm{~g}$ and shake vigorously by hand, followed by centrifugation for 20 minute at $3500 \mathrm{rpm}$ and the supernatant was carefully discarded. $20 \mathrm{ml} \pm 2 \mathrm{ml}$ sodium hexametaphosphate solution was added followed by $150 \mathrm{ml} \pm 2 \mathrm{ml}$ of water and content shake thoroughly. Sodium hexametaphosphate helps to break up the soil aggregates. The resulting sample was shake endover-end for $18 \mathrm{hr}$. The various textural fractions were determined by integration of sieving and sedimentation. The results are displayed in Table 1.

Table 1. Soil physiochemical properties for representative samples.

\begin{tabular}{llllll}
\hline Soil ID & TOC & pH & Textural class & Sand \% & Silt \% \\
\hline IK1 & 5.090 & 5.6 & Silty clay loam & 12 & Clay \% \\
IK11 & 10.815 & 6.1 & Silty clay & 11 & 32 \\
IK23 & 3.933 & 5.8 & Clay loam & 25 & 47 \\
IK32 & 3.380 & 5.9 & Clay loam & 21 & 46 \\
IK48 & 6.749 & 5.9 & Clay & 6 & 45 \\
IK52 & 5.795 & 6.0 & Clay & 1 & 34 \\
IK68 & 5.299 & 5.2 & Silty clay & 6 & 41 \\
IK76 & 3.759 & 5.5 & Silty clay loam & 18 & 57 \\
IK79 & 4.255 & 5.5 & Silty clay & 14 & 58 \\
IK81 & 5.455 & 5.4 & Silty clay loam & 6 & 36 \\
\hline
\end{tabular}

$\mathrm{TOC}=$ total organic content, $\mathrm{IK}=\mathrm{Ik}$ arama

\subsection{Vis-NIR DRS Analysis}

Three subsamples were packed into plastic Petri dishes from each of the 82 soil samples for vis-NIR DRS sampling. This was done to generate multiple spectral information for the purpose of averaging. To obtain optimal diffuse reflection, and hence, a good signal-to-noise ratio [13], all plant and pebble particles were removed and surface smoothened gently with a spatula for sampling. An Analytical Spectral Device (ASD) spectrometer (ASDI, USA) with a spectral range of 350 to $2500 \mathrm{~nm}$ was used for sampling in the laboratory. The equipment was started and allowed to warm up for at least 30 minutes and calibrated with a white reference before soil spectral measurement. VisNIR DRS of all the samples were recorded with the spectrometer by placing the sample in direct contact with a high intensity probe built in a halogen light source. White referencing was taken at every time interval of 30 minutes while sampling to avoid saturation of the detector, and possibly remove dark current and ambient temperature humidity variation effects as reported [11].

\subsection{Hydrocarbon Analysis}

Petroleum hydrocarbons extraction and GC-MS analysis adopted in the current study followed the approached previously described [14] with some modification. $5 \mathrm{~g}$ soil sample was weighed and mixed with $20 \mathrm{ml}$ dichloromethane (DCM) and hexane (Hex) mixture (1:1) and shake properly with flask shaker for $16 \mathrm{hr}$ at 150 oscillations to break up and mix the sample matrix. The resulting sample was sonicated for 30 minutes at $20^{\circ} \mathrm{C}$, followed by centrifugation for $5 \mathrm{~min}$ at 750 rpm to sediment the soil. The supernatant was decanted into a filter paper (to retain the filtrate i.e., the sample) through sodium sulphate $\left(\mathrm{Na}_{2} \mathrm{SO}_{4}\right) .2 \mathrm{ml} \mathrm{DCM} / \mathrm{Hex}(1: 1)$ was used to condition the cartridge and the sample was loaded and another filtrate was retained. This filtrate was placed in an ice basin and dried with nitrogen gas $\left(\mathrm{N}_{2}\right) .0 .5 \mathrm{ml}$ of DCM/Hex mixture (1:1) was added to the sample, shake (manually) properly and pipette into a vial. The final extract was diluted with a dilution factor of 1:10 for GC-MS analysis.

Analysis of $\mathrm{PAH}$ and alkanes were carried out with Agilent 5973N GC/MS gas chromatography. For quality control purpose, analytical blanks DCM/Hex (1:1) were analysed. This was followed by calibration using deuterated PAHs $\left(1,4\right.$ dichlorobenzene- $\mathrm{d}_{4}$, phenantrene- $\mathrm{d}_{10}$, acenaphtene- $\mathrm{d}_{10}$, chrysene- $\mathrm{d}_{12}$, perylene- $\mathrm{d}_{12}$, and naphtalene$\mathrm{d}_{8}$ ). Both PAH and alkanes were measured in positive ion mode with an ionisation energy of $70 \mathrm{eV}$ and quantified by auto-integration method with Mass Selective Detector (MSD) ChemStation software. The limit of quantification (LOQ) customarily used for PAH in Nigerian laboratories $(0.02 \mathrm{mg} / \mathrm{kg})$ was adopted for this study because samples were collected from Nigeria. As such, any value below 0.02 $\mathrm{mg} / \mathrm{kg}$ was ignored for the PAH computation. Data analyses (e.g. minimum, maximum, median and standard deviation concentrations) were performed in this study. To investigate the statistical significance the hydrocarbon profiles and concentrations of the samples collected in the tilled 
(ploughed) and un-tilled area, Principal Component Analysis (PCA) and non-metric Multidimensional scaling (nMDS) were carried out using Primer version 6. To assess the relationship between hydrocarbon profiles and concentration, the Spearman's rank correlation was performed.

\section{Results and Discussion}

\subsection{Hydrocarbon Profiles and Concentration of the Soil Samples Collected in the Tilled and Untilled Area}

GC-MS was used to analyse alkanes and PAHs in untilled and tilled (ploughed) oil-contaminated soils. Results showed that the allkanes concentrations in the untilled and tilled (ploughed) sites range from 0.07 to $528.1 \mathrm{mg} / \mathrm{kg}$ and 0.06 to $159.3 \mathrm{mg} / \mathrm{kg}$, respectively. For the PAHs, the concentrations range from 0.05 to $48.5 \mathrm{mg} / \mathrm{kg}$ and 0.04 to $0.742 \mathrm{mg} / \mathrm{kg}$ for untilled and tilled (ploughed) sites, respectively. It was observed that out of the 62 untilled samples, Alkane concentrations were detected in 61 samples; however, 35 samples contain only $\mathrm{nC}_{10}$ hydrocarbons. Two (2) samples contain no $\mathrm{nC}_{10}$ hydrocarbons. Similarly, for the 20 tilled (ploughed) samples analysed, 11 samples contain only $\mathrm{nC}_{10}$ hydrocarbons. This implies that $\mathrm{nC}_{10}$ hydrocarbon is prevalent in the studied site. It was observed that, out of 62 untilled samples, PAH was detected in only 17 samples. Similarly, for the 20 tilled (ploughed) samples, PAH was detected in only 3 samples. This implies that $27 \%$ and $15 \%$ concentrations of PAHs were present in the untilled and tilled (ploughed) sites, respectively. The rest might have been lost through volatilisation or degradation, or both.

In this study, 13 PAHs (3- to 6- ring) out the 16 EPA identified priority PAHs were detected. Results show that 3to 4- ring (ACEN, FLU, ANTH, PHEN, PYr, CHs, BaA) PAHs had higher concentrations compared to 5- to 6- ring PAHs (BaPYr, BghiPE, BbF, BkF, DahA, IDA) by 19.87 folds. Figure 2 displays the PAHs concentrations for the studied site. This trend is in line the results of [6], which might be attributed to the fact that the HMM PAHs eluted the GC-MS column after the LMM PAHs because of their longer retention times.

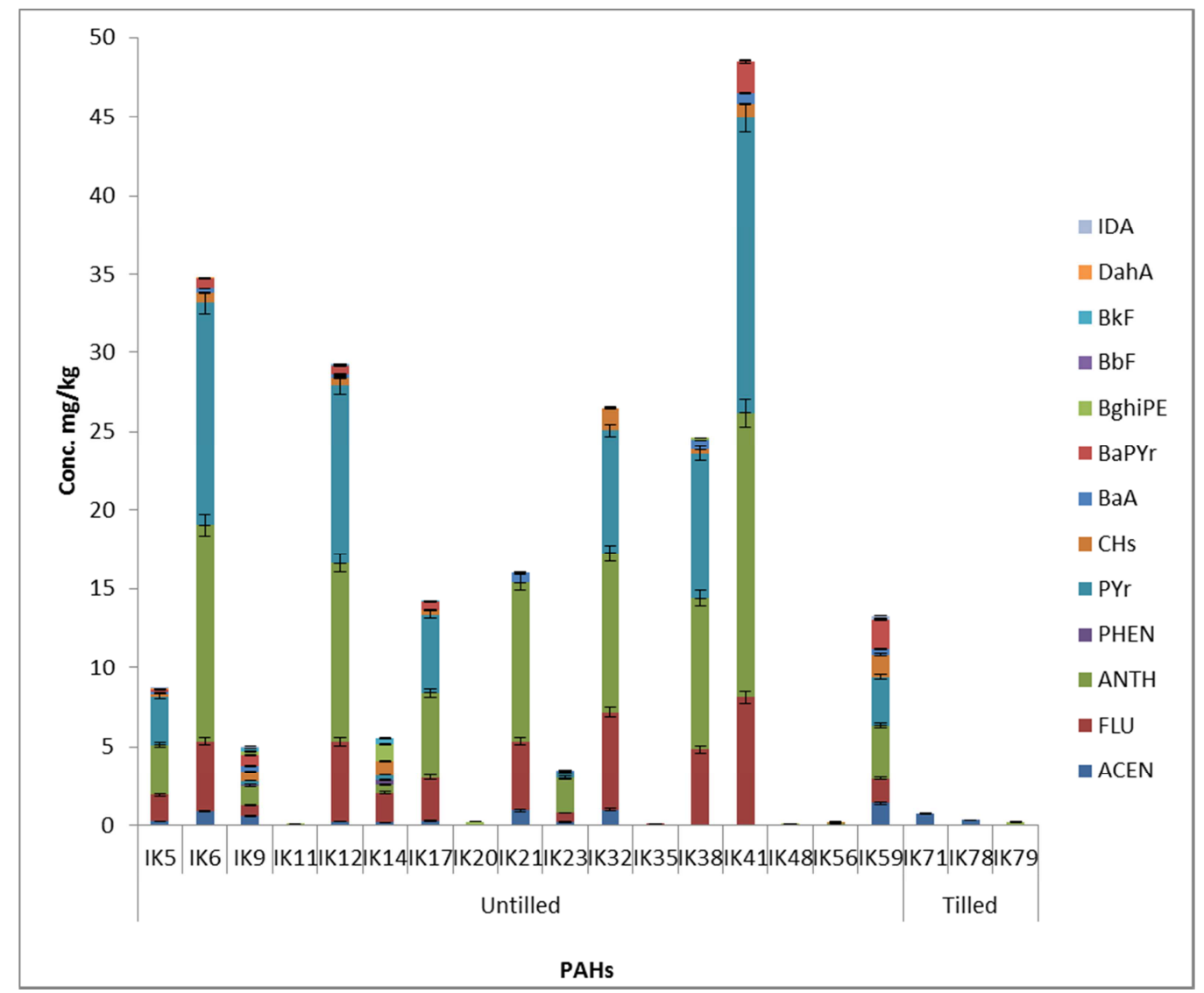

Figure 2. PAHs concentrations for studied site. The PAH distribution is mainly dominated by anthracene (3 ring PAH), followed by pyrene (4 ring PAH), fluorene (3 ring PAH), benzo [a] pyrene (5 ring PAH) and chrysene (4 ring PAH). ACEN=Acenaphthylene, FLU= Fluorene, ANTH=Anthracene, PHEN=Phenanthrene, $P Y r=$ Pyrene, $C H s=$ Chrysene, BaA=Benzo [a] anthracene, BaPYr=Benzo [a] pyrene, BghiPE=Benzo [g, $h, i]$ perylene, BbF=Benzo [b] fuoranthrene, DahA=Dibenzo [a, h] athracene, IDA=Indeno [1, 2, 3-c, d] pyrene.

Analysis shows that the TPH concentration $(666.3 \mathrm{mg} / \mathrm{kg})$ in the study site exceeded the target value $(50 \mathrm{mg} / \mathrm{kg})$ but less than the intervention level $(5,000 \mathrm{mg} / \mathrm{kg})$ placed by Environmental Guideline and Standards for the Petroleum
Industry in Nigeria [15].

Sorbent particle size, pore throat size and the total organic content of soil are critical factors affecting the movement of PHCs in soil. If the particles that sorb the 
PAH cannot move through the pore throat of the soil, then PAHs will be retained in the soil. In addition, the properties of the PAH determine its sorption rate to the soil [16] total organic content (TOC) and clay content (CC) of the soil also significantly influence the mobility of PAHs in the soil environment. However, in this study the observed variation in terms of PAH and alkane concentrations in the two set of soil samples might not due the available TOC or CC as representative soil samples covering the entire study site were analysed for these two pertinent properties, among others; and no significant variability was observed (Table 2). Reason may be that, tilling (ploughing) might have enhanced fast volatilisation of the low molecular mass hydrocarbons or weathering of the hydrocarbons. Other factors such as octanol-water portioning coefficient $\left(\mathrm{K}_{\mathrm{ow}}\right)$, soil conductivity may influence PAH movement in soil [16]. However, this study does not use these parameters for decision-making.

Table 2. The minimum, maximum, mean, and standard deviation of soil properties.

\begin{tabular}{|c|c|c|c|c|c|c|}
\hline Soil status & Number of samples & Soil properties & Min. value & Max. value & Mean & STDEV \\
\hline \multirow{5}{*}{ Untilled } & \multirow{5}{*}{6} & TOC & 3.38 & 10.82 & 5.96 & 2.67 \\
\hline & & $\mathrm{pH}$ & 5.60 & 6.10 & 5.88 & 0.17 \\
\hline & & Sand $\%$ & 1.00 & 25.00 & 12.67 & 9.00 \\
\hline & & Silt $\%$ & 34.00 & 56.00 & 44.83 & 7.25 \\
\hline & & Clay $\%$ & 28.00 & 60.00 & 42.17 & 13.72 \\
\hline \multirow{4}{*}{ Tilled (ploughed) } & \multirow{4}{*}{4} & $\mathrm{pH}$ & 5.20 & 5.50 & 5.40 & 0.14 \\
\hline & & Sand $\%$ & 6.00 & 18.00 & 11.00 & 6.00 \\
\hline & & Silt $\%$ & 50.00 & 63.00 & 55.50 & 5.80 \\
\hline & & Clay\% & 31.00 & 36.00 & 33.00 & 2.16 \\
\hline
\end{tabular}

Table 3 below showed the GC-MS analysed alkanes from untilled and tilled (ploughed) soils contaminated with petroleum hydrocarbons. Results show that $\mathrm{nC}_{10^{-}}$ $\mathrm{nC}_{12}, \quad \mathrm{nC}_{12}-\mathrm{nC}_{16}, \quad \mathrm{nC}_{16}-\mathrm{nC}_{21}, \quad \mathrm{nC}_{21}-\mathrm{nC}_{30}, \quad \mathrm{nC}_{30}-\mathrm{nC}_{40}$ for untilled samples had concentrations $4.8,5.5,8,6.7$, and 9.4 times more than their counterparts (i.e., tilled samples).
Similarly, for phytane and pristine (branched chain alkanes), the untilled samples had concentrations 11 and 19 times higher than phytane and pristine in the tilled samples. This wide spread variability may be that, tilling (ploughing) operation might have favoured weathering and/or degradation processes.

Table 3. GC-MS quantification of alkanes from untilled and tilled (ploughed) soil contaminated with hydrocarbons.

\begin{tabular}{|c|c|c|c|c|}
\hline Soil analysed & Soil type & Soil containing alkanes & Alkanes & Sum [conc. $(\mathrm{mg} / \mathrm{kg})]$ \\
\hline \multirow{6}{*}{62} & \multirow{6}{*}{ Untilled } & \multirow{6}{*}{62} & $\mathrm{nC}_{10}-\mathrm{nC}_{12}$ & 210 \\
\hline & & & $\mathrm{nC}_{12}-\mathrm{nC}_{16}$ & 1037 \\
\hline & & & $\mathrm{nC}_{21}-\mathrm{nC}_{30}$ & 2731 \\
\hline & & & $\mathrm{nC}_{30}-\mathrm{nC}_{40}$ & 356 \\
\hline & & & Phytane & 245 \\
\hline & & & Pristane & 757 \\
\hline \multirow{6}{*}{20} & \multirow{6}{*}{ Tilled (ploughed) } & \multirow{6}{*}{17} & $\mathrm{nC}_{10}-\mathrm{nC}_{12}$ & 44 \\
\hline & & & $\mathrm{nC}_{12}-\mathrm{nC}_{16}$ & 189 \\
\hline & & & $\mathrm{nC}_{16}-\mathrm{nC}_{21}$ & 149 \\
\hline & & & $\mathrm{nC}_{21}-\mathrm{nC}_{30}$ & 406 \\
\hline & & & $\mathrm{nC}_{30}-\mathrm{nC}_{40}$ & 38 \\
\hline & & & Phytane & 22 \\
\hline
\end{tabular}

The minimum, maximum, and median concentrations $(\mathrm{mg} / \mathrm{kg}$ ) of hydrocarbons (alkane, PAH and TPH) in oil contaminated soils are presented in Table 4 below. Results show a relative variability between the untilled and tilled (ploughed) soil samples. This variability may be explaining that weathering and/or degradation processes might have been influenced by tillage (ploughing).

Table 4. The minimum, maximum, and median concentrations of total petroleum hydrocarbons (TPH) (mg/kg) in genuine oil contaminated soils.

\begin{tabular}{llllll}
\hline Soil status & Number of samples & Hydrocarbons & Minimum value & Maximum value & Median \\
\hline Untilled & 43 & TPH & 26.5 & 666.3 \\
Tilled (ploughed) & 6 & TPH & 18.7 & 364.2 \\
\hline
\end{tabular}




\subsection{Non-metric Multidimensional Scaling (nMDS) and PCA Investigation}

Non-metric Multidimensional Scaling (nMDS) and PCA were applied on GC-MS-based hydrocarbon data using Primer version 6 to investigate the statistical significance of the hydrocarbon profiles and concentrations of the samples collected from the untilled and tilled sites. The aim was to find a pattern explanation on the distribution of the samples based on alkane, PAH and TPH. With nMDS, it was observed that a few untilled and tilled samples overlap indicating the change in hydrocarbon content and concentrations. However, samples were grouped based on hydrocarbon content. That is, group A samples had alkane, PAH, and TPH while group B samples had alkane and TPH (Figure 3). Overall, there is clear distribution of the two set of samples in terms of hydrocarbon contents.

Transform: $\log (X+1)$ Resemblance: $\$ 1$ Simple matching

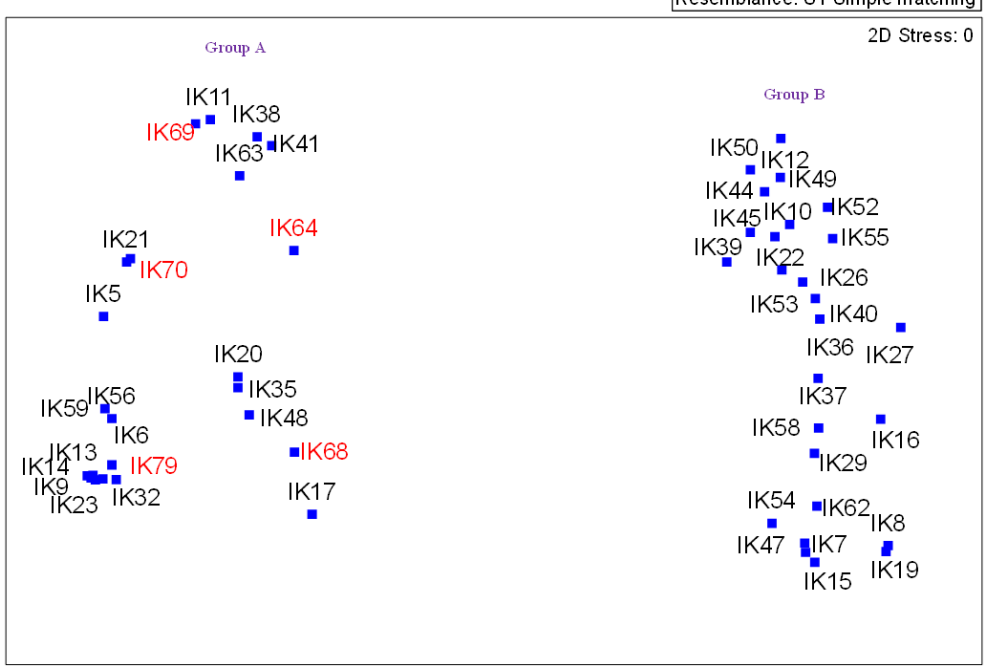

Figure 3. Non-metric Multidimensional Scaling (nMDS) investigation of pattern explanation on the distribution of hydrocarbons in untilled and tilled (ploughed) sites.

PCA was able separate the samples into groups A, B and C based on hydrocarbon content and concentrations (Figure 4). Samples in the inner portion of the ring had alkane, PAH and TPH, while those that clustered around the upper portion of the ring (i.e. group A) had alkane and PAH except sample IK11 had $0.5 \mathrm{mg} / \mathrm{kg}$ PAH. Those outside the ring and close to positive end of PC2 had high concentrations of alkane but no PAH (group A). The samples at the positive side of PC1 (group $\mathrm{C}$ ) had alkane, PAH and TPH but with relatively low concentrations, whereas the samples at the top right end of the PC plot (group B) had only alkane except samples IK20, IK35, and IK56 that had both alkane, PAH, and TPH though with very low concentrations. Their separation from those in the inner portion of the ring may be attributed to their significantly low concentrations. From the forgoing, PCA was able to show distribution of the samples based on hydrocarbon content and concentrations. This study has provided new window opportunity for grouping hydrocarbon contaminated soils into hydrocarbon content and concentrations by vis-NIR spectroscopy.

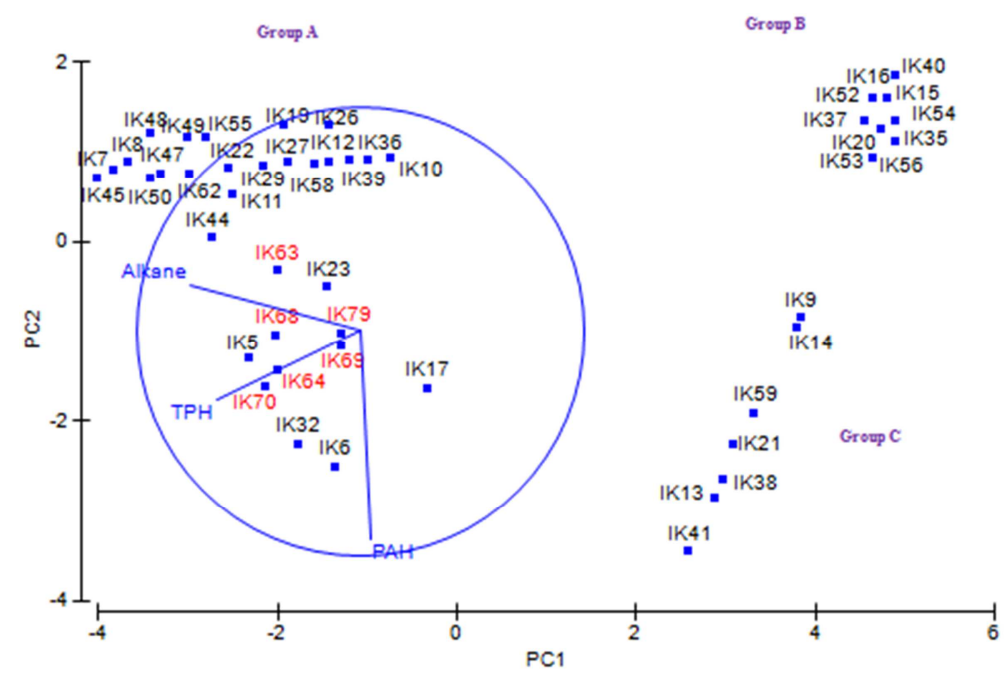

Figure 4. PCA investigation of the hydrocarbon profiles and concentrations of samples collected from untilled and tilled (ploughed) sites. 


\subsection{Vis-NIR Spectroscopy Profiles}

Principal Component Analysis (PCA) was performed on the Vis-NIR-based soil spectral data set using chemometric. Figure 5 shows the PCA scores. PC1 accounted for $59.53 \%$ of the total variance between the samples, while PC2 accounted for $15.78 \%$ of the variation. Some degree of overlap was observed among the untilled and tilled samples. This overlap may be due to change in hydrocarbon content and concentrations as was observed in the case of GC-MS hydrocarbon data. However, this technique allowed a quite satisfactory distribution of the samples based on hydrocarbon content and concentrations in the studied site. This is in line with [10] findings, regarding the ability of PCA to separate between contaminated and noncontaminated soils. The distribution pattern of the hydrocarbons here agrees with the pattern achieved with the Primer version 6 in this present study, except sample numbers 6 and 44 that are far separated. This separation may be attributed to soil properties, particularly clay content which significantly influences hydrocarbon calibration [12].
To investigate the basis of the observed spectral discrimination between the untilled and tilled (ploughed) soil samples, PCA loadings were analysed (Figure 6). The highest positive and negative loadings in PC1 were observed at 1870 $\mathrm{nm}$ and $1350 \mathrm{~nm}$, respectively. The $1870 \mathrm{~nm}$ was related to $\mathrm{C}=\mathrm{O}$ stretch in the second overtone, whereas the $1350 \mathrm{~nm}$ was related the first overtone of the $\mathrm{C}-\mathrm{H}$ combinations. The highest positive loadings in $\mathrm{PC} 2$ was located at $1850 \mathrm{~nm}$, which is related to the first overtone region of the $\mathrm{C}=\mathrm{O}$ stretch of the second overtone, while the highest negative loadings in $\mathrm{PC} 2$ was at $1720 \mathrm{~nm}$, which is related to the first overtone region of the $\mathrm{C}-\mathrm{H}$ bond of the first overtone.

PCA loadings were analysed to understand and spot significant wavelengths for the prediction of soil TPH and water. Figure 5 displays dip around $1715 \mathrm{~nm}$ which is related to TPH absorption in the first overtone, which agrees with [17]. The highest and positive loadings of component 1 were found around $1900 \mathrm{~nm}$ (first overtone) and $1396 \mathrm{~nm}$ (second overtone) which were related to water.

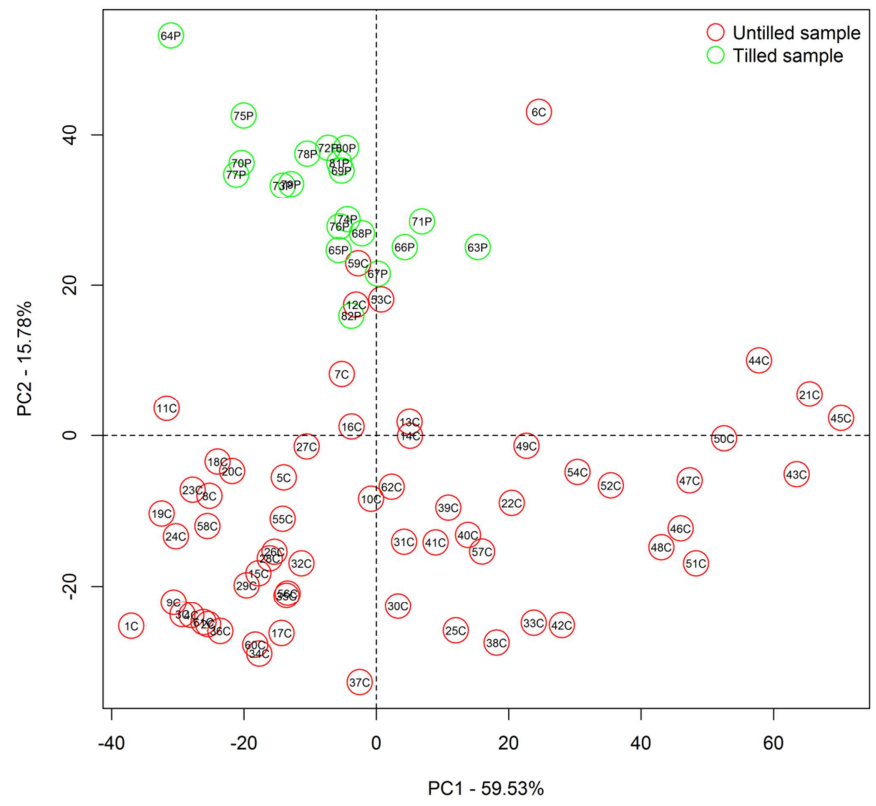

Figure 5. The similarity map of principal component analysis (PCA) based on the spectral dataset for untilled (contaminated, $C$ ) and tilled (ploughed, $P$ ) soils contaminated with petroleum hydrocarbon.

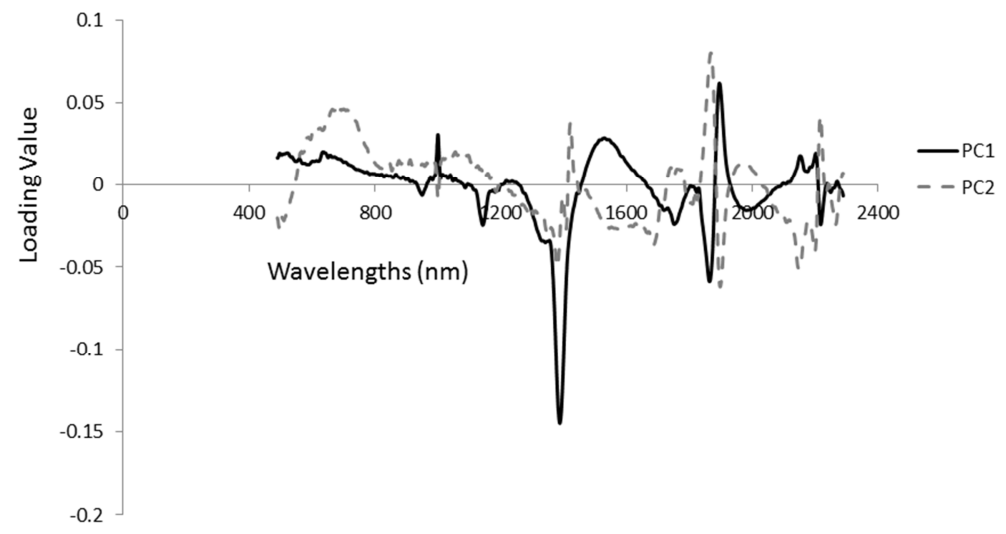

Figure 6. Spectral patterns of PC1 and PC2 for visible near infrared (vis-NIR) spectra of untilled and tilled oil contaminated soil samples. 


\section{Conclusions}

This current study assessed the potential of vis-NIR DRS to differentiate between untilled and tilled (ploughed) sites contaminated with petroleum hydrocarbon from same spill. Results obtained confirmed the following conclusions:

1. The total petroleum hydrocarbon (TPH) concentration, $666.3 \mathrm{mg} / \mathrm{kg}$ and $364.2 \mathrm{mg} / \mathrm{kg}$, respectively for untilled and tilled (ploughed) soils detected in the studied site exceeded target level $(50 \mathrm{mg} / \mathrm{kg})$ but lower than the intervention level $(5,000 \mathrm{mg} / \mathrm{kg})$ in Nigeria. Though the extent of hydrocarbon contamination is below the intervention level, each oil spill incidence is unique and therefore dynamic risk assessment it is imperative at all spill sites to benefit the quality of lives and livelihoods of the people living in and around such environment.

2. Tilling (ploughing) of oil contaminated soils may help to reduce contaminants' concentrations to some extent, particularly volatilisation of the lower molecular mass hydrocarbons; or might influence weathering and/or degradation processes. However, taking appropriate actions in petroleum contaminated sites is essential, since tilling alone might not help reduce the contaminant's concentration to no unacceptable risk to specified target.

3. There is a new window opportunity for grouping hydrocarbon contaminated soils into hydrocarbon content and concentrations by vis-NIR spectroscopy.

4. PCA is useful to show distribution of the samples based on hydrocarbon content and concentrations.

From the forgoing, since vis-NIR DRS is a promising tool for site investigation, pattern explanation on the distribution of hydrocarbon content and concentrations in contaminated sites, it may be useful for specific site risk-assessment informing.

\section{Acknowledgements}

The authors acknowledge the Petroleum Technology Development Fund (PTDF) of Nigeria with Grand No: PTDF/OSS/PHD/711/14, whose financial support in the form doctoral studentship has led to this publication.

\section{References}

[1] Liu, Y. L., Wen, C., Liu, X. J., 2013. China's food security soiled by contamination. Science 339, 1382-1383.

[2] Luo, X.-S., Yu, S., Zhu, Y.-G., Li, X.-D., 2012. Trace metal contamination in urban soils of China. Sci. Total Environ. 421-422, 17-30.

[3] Cai, Q.-Y., Mo, C.-H., Wu, Q.-T., Katsoyiannis, A., Zeng, Q.Y., 2008. The status of soil contamination by semivolatile organic chemicals (SVOCs) in China: a review. Sci. Total Environ. 389, 209-224.
[4] Coulon, F., Whelan, M. J., Paton, G. I., Semple, K. T., Villa, R., Pollard S. J. T., 2010. Multimedia fate of petroleum hydrocarbons in the soil: oil matrix of constructed biopiles. Chemosphere $81 \quad$ 1454-62. doi: 10.1016/j.chemosphere.2010.08.057.

[5] Cozzolino, D., 2015. Near infrared spectroscopy as a tool to monitor contaminants in soil, sediments and water-state of the art, advantages and pitfalls. Trends Environ. Anal. Chem. doi: 10.1016/j.teac.2015.10.001.

[6] Okparanma, R. N., Coulon, F and Mouazen, A. M., 2014. Analysis of petroleum-contaminated soils by diffuse reflectance spectroscopy and sequential ultrasonic solvent extraction-gas chromatography. Environmental Pollution 184, 298-305.

[7] Okparanma, R. N., Coulon, F., Mayr, T and Mouazen, A. M., 2014. Mapping polycyclic aromatic hydrocarbon and total toxicity equivalent soil concentrations by visible and nearinfrared spectroscopy. Environmental Pollution 192, 162-170.

[8] Okparanma, R. N., Mouazen, A. M., 2013. Combined Effects of Oil Concentration, Clay and Moisture Contents on Diffuse Reflectance Spectra of Diesel-Contaminated Soils. Water, Air, Soil Pollut. 224, 1539-8. doi: 10.1007/s11270-013-1539-8

[9] Bray, J. G. P., Rossel, R. V., McBratney, A. B., 2009. Diagnostic screening of urban soil contaminants using diffuse reflectance spectroscopy. Soil Res. 47, 433-442.

[10] Chakraborty, S., Weindorf, D. C., Morgan, C. L. S., Ge, Y., Galbraith, J. M., Li, B., 2010. Rapid identification of oilcontaminated soils using visible near-infrared diffuse reflectance spectroscopy. Journal of Environmental Quality $39,1378-1387$.

[11] Forrester, S., Janik, L., \& McLaughlin, M., 2010. An infrared spectroscopic test for total petroleum hydrocarbon (TPH) contamination in soils. In Proceedings of the 19th world congress of soil science, soil solutions for a changing world (pp. 13-16), August 1-6. Brisbane, Australia.

[12] Schwartz, G., Ben-Dor, E., Eshel, G., 2012. Quantitative analysis of total petroleum hydrocarbons in soils: comparison between reflectance spectroscopy and solvent extraction by 3 certified laboratories. Applied and Environmental Soil Science 1-11.

[13] Mouazen, A. M., De Baerdemaeker, J., Ramon, H., 2005. Towards development of on-line soil moisture content sensor using fibre-type NIR Spectrophotometer. Soil Tillage Res. 80, 171-183.

[14] Risdon, G. C., Pollard, S. J. T., Brassington, K. J., McEwan, J. N., Paton, G. I., Semple, K. T., and Coulon, F., 2008. Development of an analytical procedure for weathered hydrocarbon contaminated soils within a UK risk-based framework. Anal. Chem. 80, 7090-7096.

[15] Department of Petroleum Resources (DPR), 2002. Environmental Guidelines and Standards for the Petroleum Industry in Nigeria (EGASPIN).

[16] Hussein, I., A and Mona, S. M. M., 2016. A review on ploycyclic aromatic hydrocarbons: Source, environmental impact, effect on human health and remediation. Egyptian Journal of Petroleum 25, 107-123.

[17] Workman Jr., J., Weyer, L., 2008. Practical Guide to Interpretive Near-infrared Spectroscopy. CRC Press, Taylor and Francis Group, Boca Raton, FL, USA. 